\title{
Multi-Parametric Optimization of WEDM Process Using Desirability Function Analysis
}

\author{
Anand Shivade ${ }^{1}$, Pravin R.Kubade ${ }^{2}$, Gurunath Shinde ${ }^{3}$ \\ Asst. Professor, Dept of Mech Engg., Gourishankar, College of Engineering, Satara ${ }^{1}$ \\ Asst. Professor, Dept of Production Engg., KIT’s, College of Engineering, Kolhapur ${ }^{2}$ \\ Asst. Professor, Mechanical Engg Department, Dr. Daulatarao Aher College of Engg., Karad, India ${ }^{3}$
}

\begin{abstract}
The present research study deals the Wire electrical discharge machining (WEDM) process for High carbon high-chromium steel (D3) with multi-parametric optimization based on the Taguchi method and desirability function analysis. Experiments were carried out based on an L9 orthogonal array. The effect of process parameter such as pulseon time (Ton), pulse-off time (Toff), current (IP) and wire speed (Ws) were analyzed on the performance measures such as material removal rate, dimensional deviation, gap current and machining time. The optimum cutting conditions are obtained by Taguchi method and desirability function. The analysis of variance (ANOVA) is applied to investigate the effect of input process parameters. Finally, the confirmation experiment was carried out for the optimal machining parameters, and the betterment has been proved.
\end{abstract}

Keywords: D3 tool steel, Desirability Function Analysis (DFA), Multi-parametric optimization, Wire Electrical Discharge Machining (WEDM).

\section{INTRODUCTION}

In mechanical industry, the demands for alloying materials having High Strength, High Hardness, High Thermal Resistance, High Abrasive Wear, more toughness, high impact resistance are increasing but, these materials are difficult to be machined by traditional machining methods. Hence, non-traditional machining methods including electrochemical machining, ultrasonic machining, electrical discharging machine (EDM) etc. are applied to machine such difficult to machine materials. WEDM is one of the most popular in all conventional EDM process, which used a wire electrode to initialize the sparking process.

In WEDM Process a small diameter wire range from 0.05 to $0.3 \mathrm{~mm}$ (Rao 2011) is applied as the tool electrode. The wire is continuously supplied from the supply spool (Fig. 1), through the work-piece, which is clamped on the table by the wire traction rollers. A gap of $0.025-0.05 \mathrm{~mm}$ is maintained constantly between the wire and work-piece. De-ionized water is applied as the dielectric fluid. A collection tank which is located at the bottom is used to collect the used wire and then discard it.

Due to the variation in dimensional accuracy wire which once used cannot be reused again. The dielectric fluid is continuously flashed through the gap along the wire, to the sparking area to remove the byproducts formed during the erosion (Kalpakjian and Schmid 2009). The WEDM is a well-established machining option for manufacturing geometrically complex or hard material parts that are extremely difficult-to-machine by conventional machining processes.

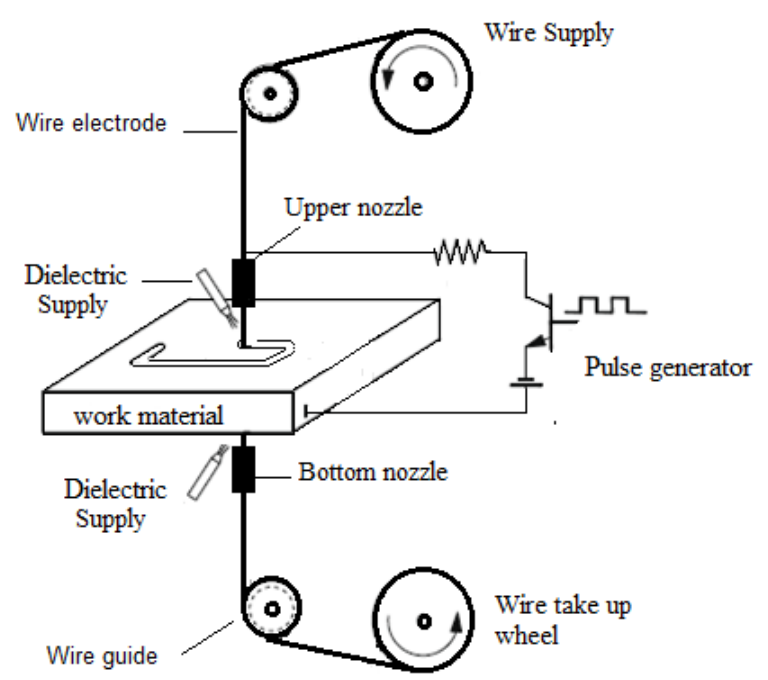

Fig 1: Representation of WEDM process

\section{EARLY DEVELOPEMENT}

In present work, the experiments were carried out on a WEDM machine (ELCTRONICA EL-CUT 334) of "Electronica Machine Tools Ltd. India". AISI D3 tool steel containing chemical composition $\mathrm{C}, 2.25 ; \mathrm{Si}, 0.60, \mathrm{Mn}, 0.60 ; \mathrm{Cr}, 12 ; \mathrm{Ni}, 0.30 ; \mathrm{W}, 1 ; \mathrm{V}, 1 ; \mathrm{Cu} 0.25 ; \mathrm{P}$, $0.03 ; \mathrm{S}, 0.03$ having $30 \mathrm{~mm}$ thickness has been selected as workpiece material. Using WEDM, work material was machined and samples were obtained in the form of rectangular punch of profile of $20 \mathrm{~mm} \times 20 \mathrm{~mm}$ square. In cutting operation, process parameters namely pulse-on time (Ton), pulse off time (Toff), Current and wire speed 
IARJSET

International Advanced Research Journal in Science, Engineering and Technology

National Conference on Design, Manufacturing, Energy \& Thermal Engineering (NCDMETE-2017)

AGTI's Dr. Daulatrao Aher College Engineering, Vidyanagar Extension, Karad

Vol. 4, Special Issue 1, January 2017

have been selected and Molybdenum wire having a fixed diameter of $0.18 \mathrm{~mm}$ has been selected as wire electrode. All cutting operation was conducted at zero wire offset setting. Distilled water having conductivity 20 mho has been utilized in the present study. High flow rate of dielectric results in complete and quick flushing of the melted debris out of the spark gap which results in high machining rate and good surface finish. Therefore, dielectric flow rate was kept at high value of 15 liters per minute. For this study four machining performance has been investigated namely Material removal rate, trial condition as per L9 OA as shown in Table 2 and dimensional deviation, gap current and machining time. result data is presented in it.

As already reported, for the present work, four process parameters each at three levels have been decided (Table: 1). The selection of a particular orthogonal array is based on the number of levels of various parameters. Now the Degree of Freedom (DOF) can be calculated by the Eq.1.

$$
(\mathrm{DOF}) \mathrm{R}=\mathrm{P} \times(\mathrm{L}-1)
$$

Where,

$(\mathrm{DOF}) \mathrm{R}=$ degree's of freedom

$$
\begin{aligned}
& \mathrm{P}=\text { number of parameters } \\
& \mathrm{L}=\text { number of levels of each parameter } \\
& \quad(\mathrm{DOF}) \mathrm{R}=4 \times(3-1)=8
\end{aligned}
$$

However, total DOF of the orthogonal array (OA) should be greater than or equal to the total DOF required for the experiment, here DOF for $\mathrm{OA}$ is 8 and DOF for experiment is also 8 , means condition is satisfied therefore L9 (34) orthogonal array is selected to assign various columns, the experiments were performed according to the

\begin{tabular}{|c|c|c|c|c|c|c|c|c|}
\hline $\begin{array}{l}\text { Ex. } \\
\text { No. }\end{array}$ & $\begin{array}{l}\text { Pulse on- } \\
\text { time }\left(T_{\text {on }}\right)\end{array}$ & $\begin{array}{l}\text { Pulse-off } \\
\left.\text { time ( } T_{\text {off }}\right)\end{array}$ & $\begin{array}{c}\text { Current } \\
\left(\mathbf{I}_{\mathbf{P}}\right)\end{array}$ & $\begin{array}{c}\text { Wire } \\
\text { speed } \\
\text { (Ws) }\end{array}$ & $\begin{array}{c}\text { MRR } \\
\text { gms/min }\end{array}$ & $\begin{array}{c}\text { Dim. } \\
\text { Deviation } \\
\%\end{array}$ & $\begin{array}{c}\text { Gap } \\
\text { current }\end{array}$ & $\begin{array}{c}\text { Machining } \\
\text { time. min }\end{array}$ \\
\hline E 1 & 3 & 2 & 1 & 3 & 17.7 & 1.655 & 0.5 & 135.62 \\
\hline E 2 & 3 & 4 & 2 & 5 & 28.6 & 1.667 & 1.3 & $\begin{array}{l}83.98 \\
\end{array}$ \\
\hline E 3 & 3 & 6 & 3 & 7 & 29.5 & 1.825 & 1.4 & 81.37 \\
\hline E 4 & 6 & 2 & 2 & 7 & 38.4 & 1.742 & 1.7 & 62.51 \\
\hline E 5 & 6 & 4 & 3 & 3 & 40.1 & 1.697 & 2.0 & 59.86 \\
\hline E 6 & 6 & 6 & 1 & 5 & 21.1 & 1.595 & 0.6 & 113.84 \\
\hline E 7 & 9 & 2 & 3 & 5 & 59.5 & 1.708 & 2.2 & 40.34 \\
\hline E 8 & 9 & 4 & 1 & 7 & 22.2 & 1.672 & 0.7 & 108.12 \\
\hline E9 & 9 & 6 & 2 & 3 & 36.4 & 1.702 & 1.7 & 65.94 \\
\hline
\end{tabular}

Table: 1 Level values of process parameters

\begin{tabular}{|c|l|c|c|c|c|}
\hline Sr. & Parameters & Unit & Level & Level & Level \\
\hline 1 & Pulse on & $\mu \mathrm{s}$ & 3 & 6 & 9 \\
\hline 2 & Pulse off & $\mu \mathrm{s}$ & 2 & 4 & 6 \\
\hline 3 & Peak & $\mathrm{Amp}$ & 1 & 2 & 3 \\
\hline 4 & Wire speed & $\mathrm{m} / \mathrm{min}$ & 3 & 5 & 7 \\
\hline
\end{tabular}

Table: 2 L9 Design matrix with experiment Results

\section{III.DESIRABILITY FUNCTION ANALYSIS (DFA)}

The desirability function approach to optimize multiple equations simultaneously was originally proposed by Harrington [19].Essentially, the approach is to translate the functions to a common scale $[0,1]$, combine them using the geometric mean and optimize the overall metric. The desirability approach involves transforming each estimated response, yi, into a unit less utility bounded by $0<\mathrm{di}<1$, where a higher 'di' value indicates that response value yi is more desirable, if $\mathrm{di}=0$ this means a completely undesired response [20].The steps involved in the optimization process are detailed below.

Step-1: The first step involves the calculation of desirability index (di) for each of the factors viz., MRR, Dimensional deviation, gap current and machining time. It is calculated based on the desirability piece wise function which is shown in Eq.2 and Eq. 3, respectively for the cases of larger the better and smaller the better. i) Larger the better

$$
\begin{gathered}
d_{i}=0, \quad y_{i} \leq \operatorname{low}_{i} \\
\left.d_{i}=\left[\frac{y_{i}-\text { low }_{i}}{\text { high }_{i}-\text { low }_{i}}\right]^{\text {wt }}\right]_{i} \\
\text { low }_{i}<y_{i}<\text { high }_{i} \\
d_{i}=1 \\
y_{i}>\text { high }_{i}
\end{gathered}
$$

The value of 'yi' is expected to be the larger the better. When the ' $y$ ' exceeds a particular criteria value, which can be viewed as the requirement, the desirability value equals to 1 ; if the ' $y$ ' is less than a particular criteria value, which is unacceptable, the desirability value equals to 0 .

$$
\begin{gathered}
d_{i}=1, \\
y_{i} \leq \operatorname{low}_{i} \\
d_{i}=\left[\frac{\text { high }_{i}-y_{i}}{\operatorname{high}_{i}-\operatorname{low}_{i}}\right]^{w t_{i}}
\end{gathered}
$$

low $_{i}<y_{i}<$ high $_{i}$

(3) 
IARJSET

$$
\begin{array}{r}
d_{i}=0 \\
y_{i}>h_{i g} h_{i}
\end{array}
$$

The value of ' $y$ ' ' is expected to be the smaller the better. When the ' $y$ ' is less than a particular criteria value, the desirability value equals to 1 ; if the ' $y$ ' exceeds a particular criteria value, the desirability value equals to 0 In this study, "larger the better" and "smaller the better" characteristics are applied to determine the individual desirability values for maximize the MRR and gap current while for minimize the dimensional deviation and machining time.

Step-2: The second step is to evaluate the composite desirability based on the Eq.4

$$
d_{G}=\left(d_{1} \times d_{2} \times \ldots \times d_{n}\right)^{\frac{1}{n}}
$$

Where, $\mathrm{n}$ is the number of responses in the measure. If any of the responses or factors falls outside their desirability range, the overall function becomes zero.

Step-3: The third step is to determine the optimal parameter and its level combination. The higher composite desirability value implies better product quality.
Therefore, on the basis of the composite desirability ( $\mathrm{dg}$ ), the parameter effect and the optimum level for each controllable parameter are estimated

Step-4: Perform ANOVA for identifying the significant parameters. ANOVA establishes the relative significance of parameters. The calculated total sum of square values is used to measure the relative influence of the parameters.

Step-5: Calculate the predicted optimum condition. Once the optimal level of the design parameters has been selected, the final step is to predict and verify the quality characteristics using the optimal level of the design parameters.

\section{IV.RESULTS AND DISCUSSION}

\section{Steps in Desirability approach and ANOVA}

Step1: The values of computed individual desirability for each quality using Eq. 2 and 3 were presented in Table 3.

Step2: The composite desirability values [dg] are calculated using Eq.4 The equal weightage of 0.25 was considered for all parameters and the calculated results are also given in Table 3 .

Table: 3 Calculation of Overall Desirability

\begin{tabular}{|c|l|l|l|l|l|}
\hline \multirow{2}{*}{ Ex No. } & \multicolumn{2}{l|}{ Individual desirability (Di) } & \multirow{2}{*}{$\begin{array}{l}\text { Composite } \\
\text { desirability (dg) }\end{array}$} \\
\cline { 2 - 5 } & MRR gms/min & Dim. Deviation & Gap current & Machining time min & 0.0000 \\
\hline 1 & 0.0000 & 0.7391 & 0.0000 & 0.0000 & 0.4623 \\
\hline 2 & 0.2607 & 0.6869 & 0.4705 & 0.5419 & 0.0000 \\
\hline 3 & 0.2822 & 0.0000 & 0.5294 & 0.5693 & 0.5577 \\
\hline 4 & 0.4952 & 0.3608 & 0.7058 & 0.7673 & 0.6763 \\
\hline 5 & 0.5358 & 0.5565 & 0.8823 & 0.7951 & 0.1818 \\
\hline 6 & 0.0813 & 1.0000 & 0.0588 & 0.2285 & 0.8445 \\
\hline 7 & 1.0000 & 0.5086 & 1.0000 & 1.0000 & 0.2220 \\
\hline 8 & 0.1076 & 0.6652 & 0.1176 & 0.2886 & 0.5928 \\
\hline 9 & 0.4473 & 0.5347 & 0.7058 & 0.7313 & \\
\hline
\end{tabular}

Step 3: In this step, the main parameter effects are characteristics. However, the relative importance among calculated and tabulated in Table 4. The factor effects are the parameters for the multiple performance characteristics plotted in Fig.2 which shows the main effects plot for the will still need to be known so that the optimal composite desirability for the different levels of the combinations of the process parameter levels can be Processing parameters. Basically, the larger the composite determined more accurately. desirability, the better is the multiple performance

Table 4: Response Table for composite desirability

\begin{tabular}{|l|l|l|l|l|}
\hline Levels & $\begin{array}{l}\text { Pulse on } \\
\text { Time (Ton) }\end{array}$ & $\begin{array}{l}\text { Pulse off } \\
\text { Time (Toff) }\end{array}$ & $\begin{array}{l}\text { peak } \\
\text { current (Ip) }\end{array}$ & $\begin{array}{l}\text { wire speed } \\
\text { (Ws) }\end{array}$ \\
\hline 1 & 0.1541 & 0.4674 & 0.1346 & 0.4230 \\
\hline 2 & 0.4719 & 0.4535 & 0.5376 & 0.4962 \\
\hline 3 & 0.5531 & 0.2582 & 0.5069 & 0.2599 \\
\hline Max- Min & 0.399 & 0.2092 & 0.403 & 0.2363 \\
\hline Ranking & 2 & 4 & 1 & 3 \\
\hline
\end{tabular}


IARJSET

Vol. 4, Special Issue 1, January 2017

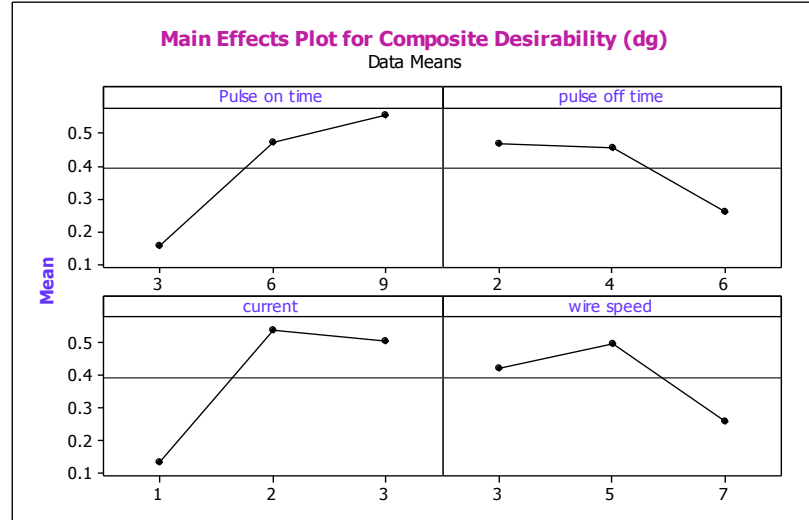

Fig: 2 Main effect plots for composite desirability index

Step 4: From Table 4 and Fig. 2, the optimum setting parameters such as $\mathrm{A} 3 \mathrm{~B} 1 \mathrm{C} 2 \mathrm{D} 2$ are obtained and also observed that, there is one particular level for each factor for which the responses are either maximum or minimum. To test the optimum setting values of desirability approach, experiments are conducted in WEDM by using the input parameters through desirability approach and corresponding outputs values of shown in Table 6 . When comparing these values with initial setting obtained in the L9 array of experiments, the desirability approach gives optimum result for all responses in one set of input.

Step 5. The calculated results of ANOVA are presented in Table 3.

$$
\begin{aligned}
\eta_{\text {opt }}=0.3930+ & (0.5531-0.3930) \\
& +(0.4674-0.3930) \\
& +(0.5376-0.3930)+(0.4962 \\
& -0.3930) \\
& \eta_{\text {opt }}=0.875
\end{aligned}
$$

\begin{tabular}{|c|c|c|c|c|}
\hline Sr. No. & Machining characteristics & Initial setting & $\begin{array}{l}\text { Predicted } \\
\text { value }\end{array}$ & $\begin{array}{l}\text { Experimental } \\
\text { value }\end{array}$ \\
\hline 1 & Optimum setting parameter & A3B1C3D2 & A3B1C2D2 & A3B1C2D2 \\
\hline 2 & MRR & 59.5 & & 58.5 \\
\hline 3 & Dimensional deviation & 1.70 & & 1.69 \\
\hline 4 & Gap current & 2.2 & & 2.1 \\
\hline 5 & Machining time & 40.34 & & 41.00 \\
\hline 6 & Composite desirability value $(\mathrm{dg})$ & 0.8445 & 0.8753 & 0.8553 \\
\hline
\end{tabular}

Table: 5 ANOVA table

\begin{tabular}{|l|l|l|l|l|l|}
\hline Parameter & $\begin{array}{l}\text { Degree of } \\
\text { freedom }\end{array}$ & $\begin{array}{l}\text { Seq. sum of } \\
\text { square }\end{array}$ & $\begin{array}{l}\text { Adj.sum of } \\
\text { square }\end{array}$ & $\begin{array}{l}\text { Adj. Mean square } \\
\text { (Variance) }\end{array}$ & $\begin{array}{l}\% \\
\text { Contribution (P) }\end{array}$ \\
\hline Pulse on time & 2 & 0.266807 & 0.266807 & 0.133404 & 36.11 \\
\hline Pulse off time & 2 & 0.082112 & 0.082112 & 0.041056 & 11.11 \\
\hline peak current & 2 & 0.301982 & 0.301982 & 0.150991 & 40.87 \\
\hline wire speed & 2 & 0.087804 & 0.087804 & 0.043902 & 11.88 \\
\hline Total & 8 & 0.738704 & & & \\
\hline
\end{tabular}

Table: 6 Predicted and experimental values

\section{CONCLUSIONS}

This work presents the experimental study on wire wire offset values $(105$ and $85 \mathrm{~lm})$ were performed after a electrical discharge machining of Monel-400, a nickel- single rough cut at high discharge energy. Results showed copper based alloy. Using desirability function, a scale- that using single trim cut at low discharge energy and free quantity called desirability has been obtained for two appropriate wire offset value, surface integrity of work performance characteristics to optimize multi-performance material can be improved successfully. characteristics, i.e., MR and SR. Corresponding to highest desirability, the optimal combination of process parameters were Ip: 103 A; Ton: 113 ls; Toff: 37 ls and SV: $50 \mathrm{~V}$. Trim cutting operations at low discharge energy (Ton: 105 ls; Toff: 35 ls; Ip: 90 A; SV: 30 V) and different

\section{REFERENCES}

[1] Kalpakjian S. and Schmid S.R., 2009. "Manufacturing process for engineering materials", Pearson education, South Asia. 
[2] Neeraj Sharmaa, Rajesh Khanna and Rahuldev Gupta, 2013. "Multi Quality Characteristics of WEDM Process Parameters with RSM", Proceeding of International Conference on DESIGN AND MANUFACTURING, Vol. 64, $710-719$.

[3] Sengottuvel.P, Satishkumar.S and Dinakaran.D, 2013. "Optimization Of Multiple Characteristics Of EDM Parameters Based On Desirability Approach And Fuzzy Modeling", Proceeding of International Conference on DESIGN AND MANUFACTURING, Vol. 64, 1069-1078.

[4] Sivaprakasam.P, Hariharan.P and Gowri.S, 2014. "Modeling and Analysis of Micro-WEDM Process on Inconel Super Alloy through Response Surface Methodology", 5th International \& 26th All India Manufacturing Technology, Design and Research Conference, 1-5.

[5] Arindam Majumder, Pankaj Kumar Das, Abhishek Majumder and Moutushee Debnath, 2014. "An approach to optimize the EDM process parameters using desirability based multi-objective PSO", Production \& Manufacturing Research, Vol. 2(1), 228-240.

[6] Anish Kumar, Vinod Kumar and Jatinder Kumar, 2012. "Prediction of Surface Roughness in Wire Electric Discharge Machining (WEDM) Process based on Response Surface Methodology", International Journal of Engineering and Technology, Vol.2 (4), 708-719.

[7] Vijayant Maan and Abhishake Chaudhary, 2013. "Optimization of Wire Electric Discharge Machining Process of D-2 Steel using Response Surface Methodology", International Journal of Engineering Research and Applications", Vol.3 (3), 206-216.

[8] Vinod Kumar, Vikas Kumar and Kamal Kumar Jangra, 2015. "An experimental analysis and optimization of machining rate and surface characteristics in WEDM of Monel-400 using RSM and desirability approach", Journal of Industrial Engineering International, DOI 10.1007/s40092-015-0103-0

[9] Anish Kumar, Vinod Kumar and Jatinder Kumar, 2013. "Multiresponse optimization of process parameters based on response surface methodology for pure titanium using WEDM process", International Journal of Advance Manufacturing Technology", DOI 10.1007/s00170-013-4861-9

[10] Alpesh M. Patel and Vishal Achwal, 2013. "Optimization of Parameters for WEDM Machine for Productivity Improvement" Journal of Mechanical and Civil Engineering, Vol. 9(5) 10-14.

[11] Taha A. El-Taweel and Ahmed M. Hewidy, 2013. "Parametric Study and Optimization of WEDM Parameters for CK45 Steel", International Journal of Engineering Practical Research (IJEPR), Vol.2 (4), 156-169.

[12] Vinod Kumar, Vikas Kumar and Kamal Kumar Jangra, 2015. “An experimental investigation and statistical modelling for trim cutting operation in WEDM of Nimonic-90",International Journal of Industrial Engineering Computations, Vol.6, 351-364.

[13] S. Raissi, and R- Eslami Farsani, 2009. "Statistical Process Optimization through Multi-Response Surface Methodology", World Academy of Science, Engineering and Technology, Vol. 27,267-271.

[14] Pravin R. Kubade, Sunil S. Jamadade, Ravindranath G. Kshirsagar and Rahul C. Bhedasgaonkar "Parametric study and optimization of WEDM parameters for Titanium diboride TiB2" IRJET Vol.:2 Issue: 4, July-2015 pp. 1-5.

[15] P. R. Kubade, S.G. Bhatwadekar, Kashid D.V. and S. B. Sangle "Investigations of Effect of Process Parameters on Material Removal Rate in Wire-cut Electrical Discharge Machining of Steel Grade EN 9" IJEERT Vol.-2, Issue 1, April 2014, pp 31-35

[16] P. R. Kubade, Palshh Patil, Akshay Bidgar, Akshay Papti, Pranav Potdar "Parametric Optimization of Abrasive Water Jet Machining of Inconel-718 material" IRJET Vol.-3, Issue 8, Aug. 2016. 